\title{
Prevalence and clinical characteristics of isolated forms of central precocious puberty: a cohort study at a single academic center
}

\author{
Carole Harbulot', Soucounda Lessim ${ }^{1}$, Dominique Simon'1, Laetitia Martinerie ${ }^{1,2}$, Caroline Storey', \\ Emmanuel Ecosse', Nicolas De Roux ${ }^{2,3}$, Jean-Claude Carel ${ }^{1,2}$ and Juliane Léger ${ }^{1,2}$ \\ ${ }^{1}$ Assistance Publique-Hôpitaux de Paris, Robert Debré University Hospital, Endocrinology-Diabetology Department, \\ Reference Center for Growth and Development Endocrine Diseases, Paris, France, ²Université de Paris, \\ NeuroDiderot, Institut National de la Santé et de la Recherche Médicale (INSERM), UMR 1141, Paris, France, and \\ ${ }^{3}$ Assistance Publique-Hôpitaux de Paris, Biochemistry Unit, Robert Debré University Hospital, Paris, France
}

Correspondence should be addressed to J Léger Email

juliane.leger@aphp.fr

\begin{abstract}
Objective: Isolated central precocious puberty (CPP) includes sporadic, familial and adoption-related forms, and the characterization of its etiology is challenging. This study investigated the prevalence and clinical characteristics of isolated CPP.

Design and methods: This observational cohort study included all patients $(n=395)$ with CPP included in the database of a single academic pediatric care center over a period of 11.5 years.

Results: In total, 332 of the 395 patients (84\%) had isolated forms of CPP; the proportion of male patients was lower in this group than for non-isolated CPP (4 vs $33 \%, P<0.0001)$. These patients had sporadic $(n=228,68.5 \%)$, familial $(n=82,25 \%)$ or adoption-related $(n=22,6.5 \%)$ forms. Clinical characteristics at diagnosis were similar between groups, but girls with sporadic CPP were older at referral than those with familial or adoption-related CPP $(P<0.02)$, and birth weight SDS was lower in adopted patients than in those from the sporadic and familial groups $(P<0.01)$. In the 72 families containing patients with familial forms, both recessive and dominant transmissions were observed between first-degree relatives. Potential maternal or paternal transmission was identified in two-thirds of the studied families, in similar proportions. An autosomal dominant mode of transmission with low penetrance was suggested by the high proportion of affected parents (33 of the 72 families, 46\%). Clinical presentation was similar whatever the mode of inheritance.

Conclusion: These findings highlight the need for careful monitoring of the various forms of CPP. Future studies should explore pathophysiological mechanisms, particularly for familial forms.
\end{abstract}

CPP is defined as premature activation of the hypothalamicpituitary-gonadal axis, with the development of secondary sexual characteristics before the age of 8 years in girls and 9.5 years in boys. Most patients have isolated forms (sporadic, familial or related to adoption) with no known underlying disorders and are considered to have 'idiopathic CPP' with no identifiable cause. Nonisolated CPP is less frequent and caused by acquired or congenital hypothalamic lesions visible on MRI or associated with various complex genetic and/or syndromic disorders $(1,2)$.

Pubertal timing is influenced by complex interactions of genetic, nutritional, environmental and socioeconomic factors $(3,4)$. Evidence of the genetic regulation of pubertal timing is provided by the strong correlation of age at onset of puberty within families and ethnic groups
Published by Bioscientifica Ltd. 
and the stronger correlation between monozygotic than between dizygotic twins (5). In recent years, significant progress has been made toward understanding the molecular mechanisms underlying the neuroendocrine control of puberty in humans $(6,7,8)$. Given recent findings concerning the genetic causes of CPP, mostly for syndromic forms (2) or isolated familial CPP, predominantly paternally transmitted with a loss of function of two imprinted genes (MKRN3 and DLK1) $(9,10)$, a clear knowledge of the different clinical forms of CPP is essential and could help to improve our understanding of the pathophysiological mechanisms underlying the precocious onset of puberty. We previously reported that non-isolated CPP is associated as frequently with syndromic disorders as with hypothalamic tumors or lesions, suggesting that several, possibly overlapping, pathophysiological mechanisms may underlie the precocious onset of puberty (11).

A few groups have described the epidemiological features of isolated CPP at their own institution $(12,13)$, at multiple institutions (14) or based on national registries, regardless of the form of CPP $(15,16,17)$. These studies have separately reported a much higher incidence in girls than in boys $(18,19,20,21)$, in sporadic and familial forms (12) or in adopted children.

The aim of this study was to investigate the different types of isolated CPP phenotypes and their prevalences in a large cohort of consecutive patients with CPP, and to determine whether clinical characteristics at diagnosis differed between the sporadic, familial and adopted groups.

\section{Patients and methods}

\section{Patients}

This observational cohort study included all Caucasian and non-Caucasian patients identified as having CPP in the database of the Pediatric Endocrinology Department of Robert Debré University Hospital in Paris over a period of 11.5 years, from January 2006 to June 2017. CPP was diagnosed on the basis of breast development before the age of 8 years in girls and testicular enlargement before the age of 9.5 years in boys, together with evaluations of serum gonadotropin-releasing hormone (GnRH) activation, based on basal serum LH levels or, much more frequently, after stimulation with exogenous GnRH or the occurrence of menarche before the age of 10 years. We excluded patients who had previously undergone brain irradiation or who had been exposed early to sex steroids.

\section{Study protocol}

Clinical data for the patients were obtained from their medical records. Demographic characteristics, including personal medical history and known associated abnormalities (e.g. neurodevelopmental or syndromic phenotypes with or without chromosomal abnormalities), sex, adoption status (living with biological or adoptive parents), consanguinity, age at first pubertal symptoms, age at first evaluation, bone age, height, weight, pubertal stage and biological data concerning puberty onset at diagnosis were recorded, together with brain MRI findings. Parental reports of the timing of puberty in first-degree (mother, father, siblings), second-degree (grandparents, uncles and aunts) and third-degree (cousins) relatives were assessed. Data for more distantly related individuals were occasionally provided by the parents. If the father never attended hospital visits with his child, the mother was asked to ask the father and/or paternal grandmother about the timing of puberty, with a view to identifying cases of CPP within the paternal pedigree. Evidence for a familial history of CPP was assessed based on age at menarche for girls (before or at 10 years old being considered precocious), and the age or timing, during or after primary school, of growth spurts or growth completion for boys, as the assessment of genital development is more complex and subjective in boys. The mothers were also asked to ask their own mothers (the maternal grandmothers) about pubertal timing in the maternal pedigree. Patients were classified as Caucasian, non-Caucasian or of unknown ethnicity. CPP cases were assigned to two groups on the basis of cause (isolated and non-isolated (CP) and then to the following categories: isolated CPP was split into sporadic CPP, familial CPP and adopted patient subgroups, and non-isolated CPP was split into a group of patients with pathological CNS features, with hypothalamic lesions on brain MRI, and a group of patients with without hypothalamic lesions on MRI, with associated syndromes and chromosomal or molecular disorders. The patients with non-isolated CPP were described in a previous study (11).

The study protocol was approved by the Ethics Review Committee for Biomedical Research Projects of Robert Debre University Hospital (no. 2014-158). Informed consent was obtained from the parents.

\section{Methods}

Precocious puberty (PP) has been defined as the onset of clinical signs of puberty before the age of 9.5 years 
in boys (testicular enlargement) and before the age of 8 years in girls (breast development), or as the occurrence of menarche before the age of 10 years. For familial forms (at least two members of the family affected), the mode of CPP inheritance was assessed and classified into four groups: (I) affected siblings only, (II) maternally (a) or paternally (b) transmitted, (III) potentially maternally (a) or potentially paternally (b) transmitted (mother or father without CPP, but CPP reported within the maternal, or paternal pedigree), (IV) more complex forms of inheritance. Inheritance was then classified as dominant (if shown to be transmitted from parents to offspring, or from generation to generation) or recessive (if CPP was observed in siblings or cousins within the same generation, only). Non-Caucasian (non-white) patients were defined as having at least one parent from Asia, sub-Saharan Africa (North African patients were considered to be Caucasian), Oceania, or Latin America.

The hypothalamic-pituitary-gonadal axis was assessed by measuring basal gonadotropins and gonadotropin responses in the GnRH stimulation test (serum LH and FSH concentrations determined at baseline and 20, 40, 60 and 90 min after the i.v. bolus administration of $100 \mu \mathrm{g} / \mathrm{m}^{2} \mathrm{GnRH}$. Central PP was diagnosed if the LH peak $>5 \mathrm{IU} / \mathrm{L}$ and/or if basal LH concentration $>0.3 \mathrm{IU} / \mathrm{L}$, and on the basis of plasma testosterone concentrations in boys and plasma estradiol concentrations in girls. Girls also underwent pelvic ultrasound scans. A longitudinal uterus diameter of more than $35 \mathrm{~mm}$, a pear-shaped uterus, and endometrial thickening were considered to be signs of estrogenic stimulation.

Height, and BMI (weight $(\mathrm{kg}) /$ height $\left(\mathrm{m}^{2}\right)$ ) were expressed as the SDS for sex and chronological age (22). Pubertal development (visual inspection and palpation of breast development in girls, and testis measurement in boys) was assessed by determining Tanner stage. Bone age was determined by the Greulich and Pyle method. Target height was calculated from mid-parental height. Each feature of the syndromic phenotypes was carefully assessed, separately. Brain MRI was performed for all patients at CPP diagnosis, to rule out nonisolated CPP. All MRI images (1.5 Tesla Magnet Philips Intera, Philips Medical Systems, The Netherlands) were reviewed by the same investigator. Sagittal and coronal thin $(1.5 \mathrm{~mm})$ slices of the hypothalamic-pituitary area were acquired with a gradient echo T1-weighted sequence and coronal slices of the brain were acquired with a T2-weighted sequence.
Hormone assays

Serum FSH and LH concentrations were determined in immunochemiluminescence assays (Siemens Healthcare SAS, Saint-Denis, France). Serum testosterone and estradiol concentrations were determined by RIA (RIA Testosterone Direct, Beckman Coulter-Immunotech, Villepinte, France and EST-US-CT, Cisbio Bioassays, Gif-sur-Yvette, France). The intra-assay coefficients of variation $(\mathrm{CV})$ were $<3.5 \%$ for $\mathrm{FSH},<4 \%$ for $\mathrm{LH},<6 \%$ for testosterone and $<10 \%$ for estradiol, and the inter-assay CVs were $<6.5 \%$ for $\mathrm{FSH},<6 \%$ for $\mathrm{LH},<12 \%$ for testosterone, and $<13.5 \%$ for estradiol.

\section{Statistical analysis}

The results are expressed as numerical values (percentages) for categorical variables and medians (25-75th percentiles) for continuous variables. Between-group comparisons were performed with Chi-squared tests for categorical variables and non-parametric Mann-Whitney or KruskalWallis tests for continuous variables. All statistical analyses were carried out with SAS software, version 9.12 (SAS Institute Inc., Cary, North Carolina).

\section{Results}

In total, 395 children were diagnosed with CPP during the study period: 361 girls (91\%) and 34 boys. These patients were assigned to two groups according to the isolated $(n=332,84 \%)$ or non-isolated $(n=63,16 \%)$ nature of their CPP. The proportion of male patients with isolated forms of CPP was significantly lower than the proportion with non-isolated CPP forms, at $4 \%$ and $33 \%$, respectively $(P<0.0001)$. The 332 patients with isolated forms of CPP comprised 228 (68.5\%) patients with sporadic forms, 82 (25\%) patients from 72 families with familial forms and $22(6.5 \%)$ adopted children (all but one adopted from abroad). The sex ratio was similar for the sporadic and familial forms of CPP. All the adopted patients with CPP were girls (Fig. 1).

The clinical characteristics of the 319 girls (boys were excluded from the analysis because they were too few in number, $n=13$ ) with isolated forms of CPP at the time of CPP diagnosis are shown in Table 1, by group (sporadic, familial or adoption-related). Birth weight for gestational age (SDS) was lower in adopted patients $(P<0.01)$, and the proportion of non-Caucasian patients was slightly higher among adopted patients than among patients 
All children with central precocious puberty (CPP) identified in the database of a single academic center over a period of 11.5 years $n=395$

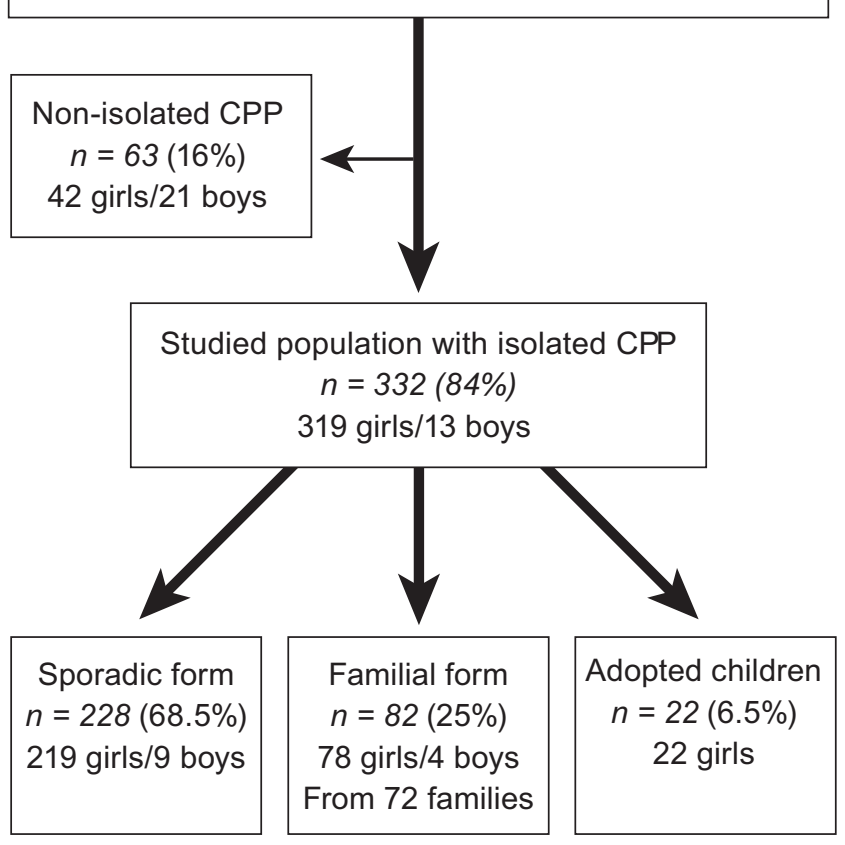

Figure 1

Flow chart of the study.

with sporadic or familial forms of CPP. Girls with sporadic forms of CPP were referred at later ages for CPP diagnosis than those from the familial and adopted groups: 8.3 (7.7; $8.8), 8.1(7.5 ; 8.8)$ and $8.0(6.6 ; 8.3)$ years, respectively $(P<0.02)$. Bone age/chronological age ratio was lower in adopted patients than in girls with sporadic and familial forms of CPP $(P<0.04)$. Other clinical characteristics were similar between groups.

The pedigrees of the families presenting familial forms of CPP are shown in Fig. 2. Consanguinity was observed in four families (families 11, 27, 33 and 60). Most familial cases were seen in families with two affected members ( $n=45$ patients from 43 families) but 29 families had three or more affected members. Both recessive and dominant modes of inheritance were observed. There were 16 families in which only siblings were affected and 33 families with affected parents and offspring. More distantly related affected family members were reported in 40 families, with 24 second-degree relatives and 23 third-degree relatives affected (with or without affected siblings within the family). Among familial forms, maternal transmission was more frequent than paternal transmission. However, the proportions of transmissions considered to be potentially maternal or potentially paternal were similar, with these forms affecting two-thirds of the studied families. An autosomal dominant mode of transmission with incomplete penetrance was suggested by the high proportion of parents affected (33 of the 72 families, 46\%). However, other modes of inheritance with recessive transmission might also be involved for familial cases in families with only affected siblings, and even more complex modes of transmission may operate in families with affected members in multiple generations without clear parent-to-child transmission in siblings. However, whatever the mode of inheritance, CPP was much more frequent in girls than in boys. No difference in clinical characteristics (such as those studied Table 1) was found between modes of inheritance in girls with familial forms of CPP (not studied in boys due to the limited number of male patients, $n=4$; data not shown). However, as expected, menarche occurred at a significantly younger age in the mothers of girls with familial CPP considered to be maternally or potentially maternally transmitted, than in those of patients with affected siblings only, with paternally or potentially paternally transmitted CPP or with a more complex mode of inheritance: $10.0(9.0-12.0)$ vs $13.0(11.5 ; 14.5), 12.5(11.3 ; 13.5)$, and $11.3(9.5 ; 13.3)$ years, respectively $(P<0.0001)$.

\section{Discussion}

This observational cohort study in well-characterized patients with CPP managed at a single academic center provides extensive data for various clinical presentations of isolated CPP. Overall, $84 \%$ of the patients in this cohort had isolated forms of CPP. One of the key contributions of this study is the prevalence analysis of cases of sporadic (68.5\%), familial (25\%) and adoption-related (6.5\%) CPP in the largest group of patients with isolated CPP ever studied. Another interesting finding was the sex dependence of penetrance, with a lower proportion of boys presenting isolated than non-isolated forms of CPP, and the significantly younger age at referral for patients with familial or adoption-related forms than for those with sporadic forms, potentially reflecting the concerns of parents about the higher risk of CPP (23) leading them to pay attention to the first clinical signs of puberty in their offspring and resulting in more urgent referral than for cases not previously informed about CPP. To our knowledge, no study assessing the clinical characteristics of isolated and idiopathic CPP in a large population of 
Table 1 Clinical characteristics of the girls at the time of isolated CPP diagnosis, by group (sporadic, familial or adoption-related). Values are expressed as median \pm quartiles, or as $n(\%)$.

\begin{tabular}{|c|c|c|c|}
\hline & Sporadic, $n=219$ & Familial, $n=78$ & Adopted, $n=22$ \\
\hline Gestational age $(w k)^{a}$ & $39(38 ; 40)$ & $39(38 ; 40)$ & $38(37 ; 41)$ \\
\hline Birth length $(S D S)^{b}$ & $-0.1(-1.0 ; 0.5)$ & $-0.1(-0.9 ; 0.5)$ & $-0.7(-3.0 ;-0.4)$ \\
\hline Birth weight $(S D S)^{c}$ & $-0.4(-1.0 ; 0.4)$ & $0.0(-0.8 ; 0.6)$ & $-1.3(-2.5 ; 0.1)^{*}$ \\
\hline \multicolumn{4}{|l|}{ Ethnicity, $n(\%)$} \\
\hline Caucasian & $50(22.8)$ & $30(38.5)$ & $3(13.6)$ \\
\hline Non-caucasian & $127(58.0)$ & $43(55.0)$ & $18(81.8)$ \\
\hline Unknown & $42(19.2)$ & $5(6.5)$ & $1(4.6)$ \\
\hline Age at evaluation (years) & $8.3(7.7 ; 8.8)$ & $8.1(7.5 ; 8.8)$ & $8.0(6.6 ; 8.3)^{\star \star}$ \\
\hline Age at puberty onset (years) & $7.0(6.5 ; 7.5)$ & $7.0(6.0 ; 7.5)$ & $7.4(5.9 ; 7.6)$ \\
\hline \multicolumn{4}{|l|}{ Tanner Stage at evaluation, $n(\%)$} \\
\hline 2 & $54(25)$ & $23(29)$ & $10(48)$ \\
\hline 3) & $117(55)$ & $44(56)$ & $11(52)$ \\
\hline 4 & 27 (13) & 9 (12) & $0(0)$ \\
\hline 5 & $15(7)$ & $2(3)$ & $0(0)$ \\
\hline Target height (SDS) & $0.5(-0.5 ; 1.3)$ & $0.0(-0.7 ; 1.2)$ & ND \\
\hline Height (SDS) & $2.6(1.6 ; 3.4)$ & $2.2(1.5 ; 3.1)$ & $1.4(0.3 ; 2.7)$ \\
\hline BMI (SDS) & $1.3(0.4 ; 2.5)$ & $1.7(0.5 ; 2.3)$ & $0.7(-0.1 ; 1.6)$ \\
\hline Bone age/chronological age (years) ratio & $1.5(1.4 ; 1.6)$ & $1.5(1.4 ; 1.7)$ & $1.4(1.3 ; 1.6)^{\star * *}$ \\
\hline LH peak (IU/L) $)^{d}$ & $11.6(7.0 ; 21.3)$ & $14.0(7.6 ; 31.7)$ & $10.6(6.5 ; 14.2)$ \\
\hline LH /FSH peak ratio & $1.1(0.6 ; 1.6)$ & $1.1(0.6 ; 1.9)$ & $0.9(0.5 ; 1.5)$ \\
\hline Estradiol (pg/mL) & $12.0(6.0 ; 23.0)$ & $13.0(6.0 ; 26.0)$ & $10(5.0 ; 23.0)$ \\
\hline
\end{tabular}

SDS: standard deviation score $* P<0.01 ; * \star P<0.02 ; * \star * P<0.04$.

Number of missing data: ${ }^{a} n=47 ;{ }^{b} n=67 ;{ }^{c} n=48 ;{ }^{d} A n$ LHRH stimulation test was not performed in 12 girls diagnosed with CPP on the basis of breast development before the age of 8 years and in 30 girls diagnosed with CPP on the basis of menarche before the age of 10 years. All these girls had basal serum LH concentrations $\geq 0.8 \mathrm{IU} / \mathrm{L}$.

patients classified into these three subgroups (sporadic, familial and adopted groups) has ever been reported, as previous epidemiological studies have analyzed patients either as a total population $(13,19,24)$ or have focused on the different subgroups separately $(12,14)$.

A positive family history of CPP was found in $25 \%$ of patients. Our estimate of the prevalence of the familial form is consistent with the findings of the most comparable previous study of patients with isolated CPP, which included 156 patients in total, 43 of whom (27.5\%) had a familial form; however, in this previous study only sporadic and familial cases were included, with adoptionrelated cases being excluded (12). Another study analyzed the characteristics of familial forms in a mixed group of early and precocious puberty cases (25). This discrepancy may have introduced bias into the estimates of various characteristics. However, predominantly maternal transmission was observed in these two previous studies, whereas we found that the proportions of potentially maternal and potentially paternal transmission were similar.

Our findings are consistent with those of these two previous studies in terms of the prediction of autosomal dominant inheritance with incomplete, sex-dependent penetrance, as demonstrated by the very small number of affected male individuals. Autosomal recessive transmission is also possible in families including only affecting siblings, and consanguinity was reported in four families. The observed patterns of transmission may also result from genetic heterogeneity.

Support for the involvement of genetic factors in the pathogenesis of isolated CPP (previously known as idiopathic CPP) was provided by recent studies implicating loss-of-function mutations of two paternally expressed imprinted genes, encoding Makorin RINGfinger protein 3 (MKRN3) and (less frequently) Deltalike homolog 1 (DLK1), in CPP pathogenesis, consistent with a crucial role of these proteins in early puberty events $(9,10)$. A high frequency of metabolic alterations, such as overweight/obesity, hyperlipidemia and earlyonset type 2 diabetes, has been reported in young adult patients with DLK1 mutations (26). Heterozygous gainof-function mutations have also been observed in both the kisspeptin gene and the gene encoding its receptor, KISS1R, but these mutations account for only very rare cases $(27,28)$. CPP due to MKRN3 and DLK1 defects displays a pattern of inheritance consistent with maternal imprinting. Pathogenic MKRN3 variants have been found in a few families, confirming that CPP can be inherited as a monogenic disorder with complete penetrance (9). 


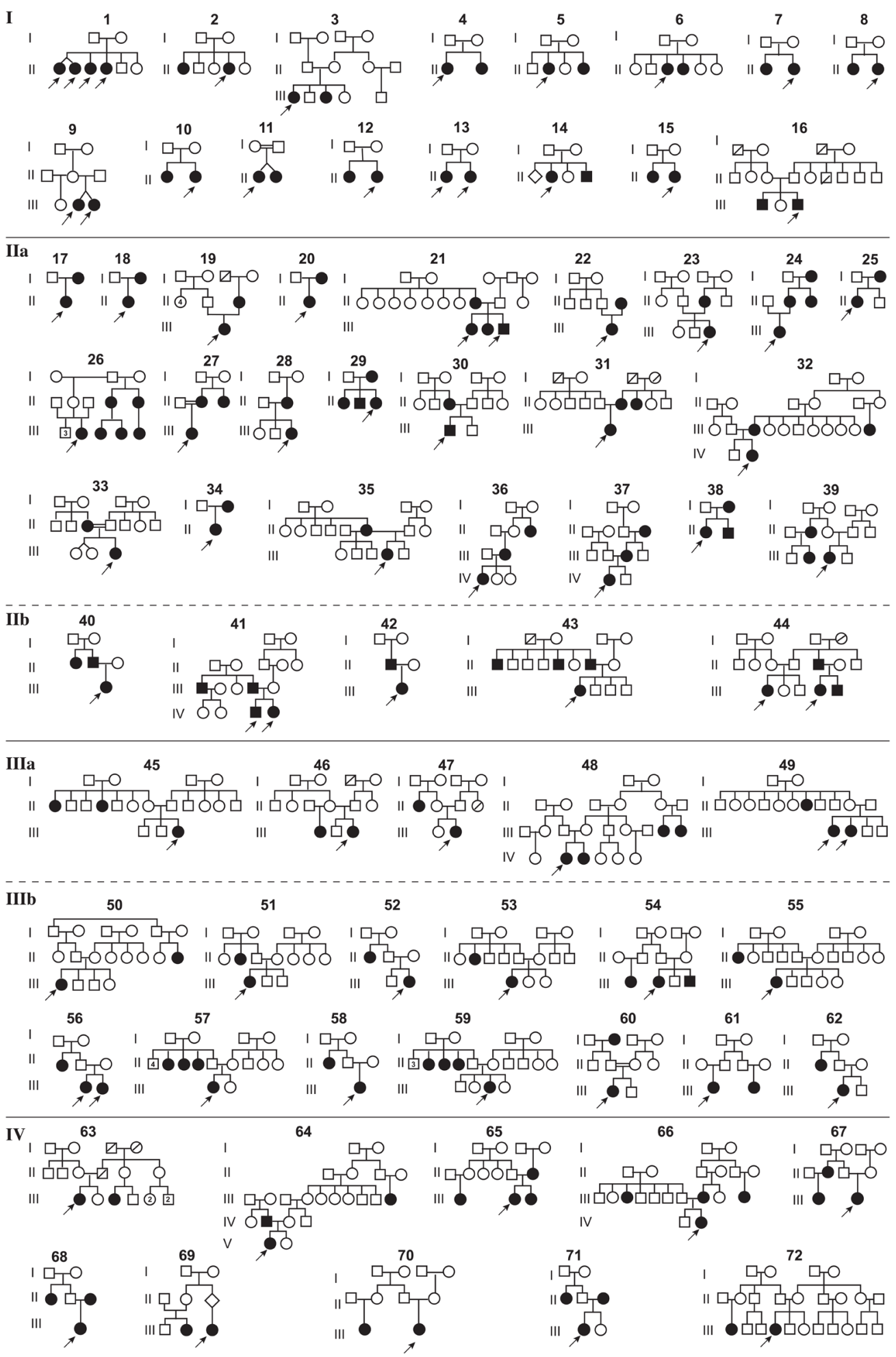

\section{Figure 2}

Pedigrees in the 72 families with members displaying isolated CPP. Individuals with black symbols have isolated CPP. Arrows indicate the 82 probands investigated in this cohort. Group I corresponds to families with affected siblings only. Group II: (a) maternally inherited; (b) paternally inherited CPP. Group III (a) potentially maternally inherited; (b) potentially paternally inherited. Group IV, with more complex inheritance. 
MKRN3 loss-of-function variants are currently the most frequent known cause of paternally inherited familial $\operatorname{CPP}(29,30)$. However, many other families were negative for MKRN3 defects, as expected in families with maternal transmission, but also in families with possible recessive or more complex transmission. This study confirms that other genes linked to CPP with complete penetrance remain to be discovered. Other imprinted genes, epigenetic modifications and/or environmental factors may also be involved $(31,32)$. The $\operatorname{Lin} 28 B$ gene and the paternally imprinted $K C N K 9$ gene have been reported to be associated with menarche timing, along with many other genes $(7,33)$. Rare variants of LIN28B and KCNK9 have been considered as potential monogenic causes of CPP, although no such variants have yet been identified in CPP cases (34). An association between Kiss1/GPR54 pathway gene polymorphism and the risk of early puberty or CPP has been reported, and should be investigated in other large populations $(35,36)$. All genes associated with age at menarche may be considered as candidate genes for CPP. Very large gene defects may lead to monogenic CPP, whereas more common variants would favor the complex transmission of CPP. Our findings highlight the need to develop research strategies suitable for polygenic or multifactorial CPP, in addition to monogenic CPP.

BMI (SDS) was similar in the sporadic, familial, and adopted cases of CPP and is therefore unlikely to be a determinant useful for distinguishing between the mechanisms of familial and sporadic cases. However, changes in BMI from birth to presentation in adopted patients, as illustrated by the lower birth weight for gestational age in our cohort, may have contributed to the early onset of puberty.

One of the major strengths of this study is the inclusion of all patients from a defined population for whom comprehensive data were collected at a single pediatric clinical center, making it possible to evaluate the contributions of all demographic, clinical and biological characteristics. We were, therefore, able to evaluate subgroups of individuals with different forms of isolated CPP. The main limitations of this study were the observational nature of the retrospective data collection and the parental reporting of pubertal development within families, with doubts about the validity of these data, particularly for boys and for the paternal pedigree $(37,38)$. Despite the inclusion of all patients with CPP, each group was small, particularly for boys, and our data provide no further insight into the clinical characteristics of the patients in the groups studied. Finally, the proportion of familial forms may have been underestimated, because some patients may erroneously have been considered to have sporadic forms because the parents were unaware of other cases within the family, or because the index case was the first child pof the family to be affected, or because their siblings were too young to have experienced CPP.

In conclusion, the results of this observational study highlight the complex interactions between multiple familial (probably genetic, at least in some cases, with genetic heterogeneity, involving many mode of transmission), ethnic, metabolic and environmental factors in precocious puberty in patients with similar clinical features of CPP. In most cases of isolated CPP, particularly in girls, CPP is considered idiopathic, but careful clinical and molecular monitoring could lead to the characterization of recently elucidated genetic factors, with a predominance of cases affected by mutations of the MKRN3 gene in paternally transmitted forms. Additional studies are required to characterize genes associated with the maternal transmission of CPP, such cases being at least as frequent, and possibly even more frequent than paternally inherited cases. The clinical implications remain limited but additional studies are required, to investigate metabolic function in the longer term, with a view to determining potential health alterations within subsets of patients related to the pathophysiology of CPP (39).

\section{Declaration of interest}

J Léger is an editor of the journal (European Journal of Endocrinology). The other authors have no conflicts of interest relevant to this manuscript to disclose.

\section{Funding}

This study was supported in part by the French Ministry of Health (Rare Disease Plan). Data collection, analysis and interpretation, and the decision to submit the paper for publication were the responsibility of the authors alone. The funding sources had no role in study design, data collection, data interpretation, data analysis, or the writing of the report.

\section{References}

1 Carel JC \& Leger J. Clinical practice. Precocious puberty. New England Journal of Medicine 2008358 2366-2377. (https://doi.org/10.1056/ NEJMcp0800459)

2 Latronico AC, Brito VN \& Carel JC. Causes, diagnosis, and treatment of central precocious puberty. Lancet: Diabetes and Endocrinology 2016 4 265-274. (https://doi.org/10.1016/S2213-8587(15)00380-0)

3 Parent AS, Teilmann G, Juul A, Skakkebaek NE, Toppari J \& Bourguignon JP. The timing of normal puberty and the age limits of sexual precocity: variations around the world, secular trends, and changes after migration. Endocrine Reviews 200324 668-693. (https:// doi.org/10.1210/er.2002-0019)

4 Sun Y, Mensah FK, Azzopardi P, Patton GC \& Wake M. Childhood social disadvantage and pubertal timing: a national birth cohort 
from Australia. Pediatrics 2017139 e20164099. (https://doi. org/10.1542/peds.2016-4099)

5 Gajdos ZK, Henderson KD, Hirschhorn JN \& Palmert MR. Genetic determinants of pubertal timing in the general population. Molecular and Cellular Endocrinology 2010324 21-29. (https://doi.org/10.1016/j. mce.2010.01.038)

6 Ojeda SR \& Lomniczi A. Puberty in 2013: unravelling the mystery of puberty. Nature Reviews: Endocrinology 201410 67-69. (https://doi. org/10.1038/nrendo.2013.233)

7 Perry JR, Day F, Elks CE, Sulem P, Thompson DJ, Ferreira T, He C, Chasman DI, Esko T, Thorleifsson G et al. Parent-of-origin-specific allelic associations among 106 genomic loci for age at menarche. Nature 2014514 92-97. (https://doi.org/10.1038/nature13545)

8 Abreu AP \& Kaiser UB. Pubertal development and regulation. Lancet: Diabetes and Endocrinology 20164 254-264. (https://doi.org/10.1016/ S2213-8587(15)00418-0)

9 Abreu AP, Dauber A, Macedo DB, Noel SD, Brito VN, Gill JC, Cukier P, Thompson IR, navarro VM, Gagliardi PC et al. Central precocious puberty caused by mutations in the imprinted gene MKRN3. New England Journal of Medicine 2013368 2467-2475. (https://doi. org/10.1056/NEJMoa1302160)

10 Dauber A, Cunha-Silva M, Macedo DB, Brito VN, Abreu AP, Roberts SA, Montenegro LR, Andrew M, Kirby A, Weirauch MT et al. Paternally inherited DLK1 deletion associated with familial central precocious puberty. Journal of Clinical Endocrinology and Metabolism 2017102 1557-1567. (https://doi.org/10.1210/jc.2016-3677)

11 Wannes S, Elmaleh-Berges M, Simon D, Zenaty D, Martinerie L, Storey C, Gelwane G, Paulsen A, Ecosse E, de Roux N et al. High prevalence of syndromic disorders in patients with non-isolated central precocious puberty. European Journal of Endocrinology 2018 179 373-380. (https://doi.org/10.1530/EJE-18-0613)

12 de Vries L, Kauschansky A, Shohat M \& Phillip M. Familial central precocious puberty suggests autosomal dominant inheritance. Journal of Clinical Endocrinology and Metabolism 200489 1794-1800. (https:// doi.org/10.1210/jc.2003-030361)

13 Mogensen SS, Aksglaede L, Mouritsen A, Sorensen K, Main KM, Gideon P \& Juul A. Diagnostic work-up of 449 consecutive girls who were referred to be evaluated for precocious puberty. Journal of Clinical Endocrinology and Metabolism 201196 1393-1401. (https:// doi.org/10.1210/jc.2010-2745)

14 Soriano-Guillen L, Corripio R, Labarta JI, Canete R, Castro-Feijoo L, Espino R \& Argente J. Central precocious puberty in children living in Spain: incidence, prevalence, and influence of adoption and immigration. Journal of Clinical Endocrinology and Metabolism 201095 4305-4313. (https://doi.org/10.1210/jc.2010-1025)

15 Teilmann G, Pedersen CB, Jensen TK, Skakkebaek NE \& Juul A. Prevalence and incidence of precocious pubertal development in Denmark: an epidemiologic study based on national registries. Pediatrics 2005116 1323-1328. (https://doi.org/10.1542/peds.2005-0012)

16 Le Moal J, Rigou A, Le Tertre A, De Crouy-Channel P, Leger J \& Carel JC. Marked geographic patterns in the incidence of idiopathic central precocious puberty: a nationwide study in France. European Journal of Endocrinology 2018178 33-41. (https://doi.org/10.1530/EJE-17-0379)

17 Kim YJ, Kwon A, Jung MK, Kim KE, Suh J, Chae HW, Kim DH, Ha S, Seo GH \& Kim HS. Incidence and prevalence of central precocious puberty in Korea: an epidemiologic study based on a National database. Journal of Pediatrics 2019208 221-228. (https://doi. org/10.1016/j.jpeds.2018.12.022)

18 Rangasami JJ \& Grant DB. Familial precocious puberty in girls. Journal of the Royal Society of Medicine 199285 497-498.

19 Prete G, Couto-Silva AC, Trivin C \& Brauner R. Idiopathic central precocious puberty in girls: presentation factors. BMC Pediatrics 2008 8 27. (https://doi.org/10.1186/1471-2431-8-27)

20 Alikasifoglu A, Vuralli D, Gonc EN, Ozon A \& Kandemir N. Changing etiological trends in male precocious puberty: evaluation of 100 cases with central precocious puberty over the last decade.
Hormone Research in Paediatrics 201583 340-344. (https://doi. org/10.1159/000377678)

21 Kim SH, Huh K, Won S, Lee KW \& Park MJ. A significant increase in the incidence of central precocious puberty among Korean girls from 2004 to 2010. PLoS ONE 201510 e0141844. (https://doi.org/10.1371/ journal.pone.0141844)

22 Rolland-Cachera MF, Cole TJ, Sempe M, Tichet J, Rossignol C \& Charraud A. Body mass index variations: centiles from birth to 87 years. European Journal of Clinical Nutrition 199145 13-21.

23 Teilmann G, Pedersen CB, Skakkebaek NE \& Jensen TK. Increased risk of precocious puberty in internationally adopted children in Denmark. Pediatrics 2006118 e391-e399. (https://doi.org/10.1542/ peds.2005-2939)

24 Chemaitilly W, Trivin C, Adan L, Gall V, Sainte-Rose C \& Brauner R. Central precocious puberty: clinical and laboratory features. Clinical Endocrinology 200154 289-294. (https://doi.org/10.1046/j.13652265.2001.01229.x)

25 Durand A, Bashamboo A, McElreavey K \& Brauner R. Familial early puberty: presentation and inheritance pattern in 139 families. $B M C$ Endocrine Disorders 201616 50. (https://doi.org/10.1186/s12902016-0130-x)

26 Gomes LG, Cunha-Silva M, Crespo RP, Ramos CO, Montenegro LR, Canton A, Lees M, Spoudeas H, Dauber A, Macedo DB et al. DLK1 is a novel link between reproduction and metabolism. Journal of Clinical Endocrinology and Metabolism 2019104 2112-2120. (https:// doi.org/10.1210/jc.2018-02010)

27 Teles MG, Bianco SDC, Brito VN, Trarbach EB, Kuohung W, Xu S, Seminara SB, Mendonca BB, Kaiser UB \& Latronico AC. A GPR54activating mutation in a patient with central precocious puberty. New England Journal of Medicine 2008358 709-715. (https://doi. org/10.1056/NEJMoa073443)

28 Silveira LG, Noel SD, Silveira-Neto AP, Abreu AP, Brito VN, Santos MG, Bianco SDC, Kuohung W, Su S, Gryngarten M et al. Mutations of the KISS1 gene in disorders of puberty. Journal of Clinical Endocrinology and Metabolism 201095 2276-2280. (https:// doi.org/10.1210/jc.2009-2421)

29 Simon D, Ba I, Mekhail N, Ecosse E, Paulsen A, Zenaty D, Houang M, Jesuran-Perelroizen M, de Filippo GP, Salerno M et al. Mutations in the maternally imprinted gene MKRN3 are common in familial central precocious puberty. European Journal of Endocrinology 2016 174 1-8. (https://doi.org/10.1530/EJE-15-0488)

30 Valadares LP, Meireles CG, De Toledo IP, Santarem de Oliveira R, Goncalves de Castro LC, Abreu AP, Carroll RS, Latronico AC, Kaiser UB, Guerra ENS et al. MKRN3 mutations in central precocious puberty: a systematic review and meta-analysis. Journal of the Endocrine Society 20193 979-995. (https://doi.org/10.1210/js.2019-00041)

31 Leka-Emiri S, Chrousos GP \& Kanaka-Gantenbein C. The mystery of puberty initiation: genetics and epigenetics of idiopathic central precocious puberty (ICPP). Journal of Endocrinological Investigation 201740 789-802. (https://doi.org/10.1007/s40618-017-0627-9)

32 Bessa DS, Maschietto M, Aylwin CF, Canton APM, Brito VN, Macedo DB, Cunha-Silva M, Palhares HMC, de Resende EAMR, Borges MF et al. Methylome profiling of healthy and central precocious puberty girls. Clinical Epigenetics 201810 146. (https:// doi.org/10.1186/s13148-018-0581-1)

33 Ong KK, Elks CE, Li S, Zhao JH, Luan J, Andersen LB, Bingham SA, Brage S, Smith GD, Ekelund U et al. Genetic variation in LIN28B is associated with the timing of puberty. Nature Genetics $2009 \mathbf{4 1}$ 729-733. (https://doi.org/10.1038/ng.382)

34 Silveira-Neto AP, Leal LF, Emerman AB, Henderson KD, Piskounova E, Henderson BE, Gregory RI, Silveira LF, Hirschhorn JN, Nguyen TT et al. Absence of functional LIN28B mutations in a large cohort of patients with idiopathic central precocious puberty. Hormone Research in Paediatrics 201278 144-150. (https://doi.org/10.1159/000342212)

35 Li D, Wu Y, Cheng J, Liu L, Li X, Chen D, Huang S, Wen Y, Ke Y, Yao Y et al. Association of polymorphisms in the kisspeptin/GPR54 
pathway genes with risk of early puberty in Chinese girls. Journal of Clinical Endocrinology and Metabolism 2020105 e1458-e1467. (https://doi.org/10.1210/clinem/dgz229)

36 Huijbregts L, Roze C, Bonafe G, Houang M, Le Bouc Y, Carel JC, Leger J, Alberti P \& de Roux N. DNA polymorphisms of the KiSS1 3' untranslated region interfere with the folding of a G-rich sequence into G-quadruplex. Molecular and Cellular Endocrinology 2012351 239-248. (https://doi.org/10.1016/j. mce.2011.12.014)

37 Rasmussen AR, Wohlfahrt-Veje C, Tefre de Renzy-Martin K, Hagen CP, Tinggaard J, Mouritsen A, Mieritz MG \& Main KM.
Validity of self-assessment of pubertal maturation. Pediatrics 2015 135 86-93. (https://doi.org/10.1542/peds.2014-0793)

38 Campisi SC, Marchand JD, Siddiqui FJ, Islam M, Bhutta ZA \& Palmert MR. Can we rely on adolescents to self-assess puberty stage? A systematic review and meta-analysis. Journal of Clinical Endocrinology and Metabolism 2020105 2846-2856. (https://doi. org/10.1210/clinem/dgaa135)

39 Charalampopoulos D, McLoughlin A, Elks CE \& Ong KK. Age at menarche and risks of all-cause and cardiovascular death: a systematic review and meta-analysis. American Journal of Epidemiology 2014180 29-40. (https://doi.org/10.1093/aje/kwu113)

Received 28 July 2020

Revised version received 30 September 2020

Accepted 5 November 2020 